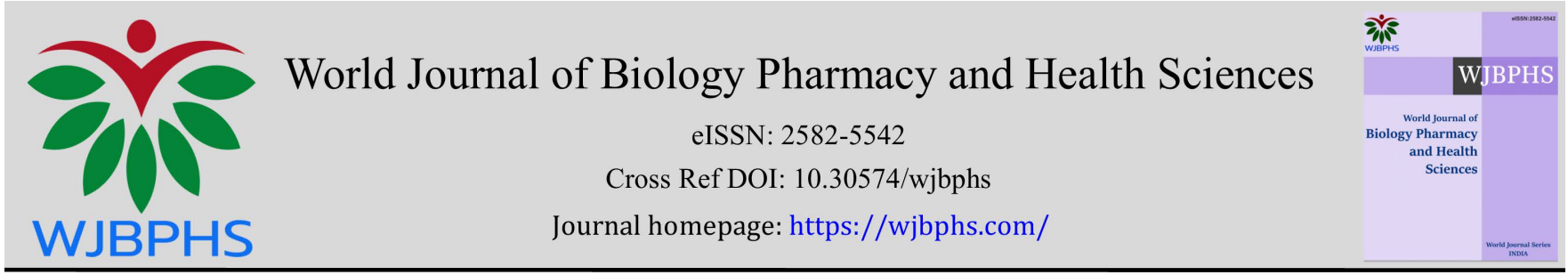

(RESEARCH ARTiCLE)

\title{
Assessment Of 2D:4D ratios amongst federal polytechnic Ekowe students, Bayelsa State, Nigeria
}

\author{
Timipa Richard Ogoun ${ }^{1,}{ }^{*}$, Pere-ere Sarah Tobia ${ }^{2}$ and Rita Osain ${ }^{1}$ \\ ${ }^{1}$ Department of Human Anatomy, Bayelsa Medical University, Yenagoa, Bayelsa State, Nigeria. \\ 2 Department of Microbiology, School of Applied Sciences, Federal Polytechnic Ekowe, Bayelsa State, Nigeria.
}

World Journal of Biology Pharmacy and Health Sciences, 2021, 08(03), 013-018

Publication history: Received on 01 November 2021; revised on 19 December 2021; accepted on 21 December 2021

Article DOI: https://doi.org/10.30574/wjbphs.2021.8.3.0126

\begin{abstract}
Humans, primates, birds and reptiles have demonstrated sexually dimorphism in the length of their 2nd and 4th digits otherwise known as 2D:4D, with males on the average having lower values than females. This difference has been associated with the differential exposure of prenatal testosterone relative to estrogen during intrauterine life. This present study assesses the $2 \mathrm{~d}$ : $4 \mathrm{~d}$ ratio amongst students of the federal Polytechnic Ekowe, Bayelsa state of Nigeria. A total of 299 students (males $n=150$ and females $n=149$ ) participated in the study. The length of 2 nd and 4 th digits were measured with digital Vernier caliper from the basal crease to the tip of the finger, and 2nd digit length (2D) was divided by 4th digit (4D) to obtain 2D:4D ratio. The results of this study showed no significant difference between 2D right and left and 4D right and left for same sex $(0.98 \pm 0.04$ and $0.98 \pm 0.04$ for males and $0.96 \pm 0.05$ and $0.96 \pm 0.05$ for female). Sexual dimorphism exits between sexes which is an indication that prenatal hormones have played a fundamental role on humans, during developmental stages.
\end{abstract}

Keywords: Sexual Dimorphism; Digit Ratio; Prenatal Testosterone

\section{Introduction}

Digit ratio is the ratio of the lengths of different digits or fingers typically measured from the midpoint of bottom crease (where the finger joins the hand) to the tip of the finger. Sexual dimorphism has been known to exist in the ratio of the second to forth finger length otherwise known as second digit to fourth digit ratio,(2D:4D) for over 100 years with men, on the average, having lower 2D:4D than women do" [1]". The ratio of the second-to-fourth digit is an attractive subject currently receiving attention from investigators. The ratio of 2 nd and 4 th fingers (2D:4D) is determined and transmitted through genetic inheritance and is related to prenatal exposure to testosterone. Research has shown that from the moment this anthropometric characteristic is determined during the 13th to 14th week of intrauterine life, it does not change either in the adolescent period or in adulthood. 2D:4D digit ratio is regarded as a physiological marker for the prenatal concentrations of the sex hormones, testosterone and estrogen, which organize the architecture of the body and the brain and the distribution of hormone receptors. Some disease conditions such as autism, depression and developmental psychopathology, congenital adrenal hyperplasia, and polycystic ovarian syndrome are also correlated with digit ratio. 2D:4D also correlates with body size and composition indices such as body mass index (BMI), chest circumference, waist circumference (WC), waist-to-hip ratio (WHR), neonatal birth weight, and hypertension. Evidence such as this does not include direct measurements of prenatal testosterone, but its sex dependent pattern led to suggest that 2D:4D may be negatively correlated to prenatal testosterone and positively related to prenatal estrogen. In recent years, the so-called second (2D) to fourth (4D) digit ratio has received a lot of research attention. In the past 7 years, many publications have documented relationship between 2D:4D and human traits and behaviours. This ratio seems to

\footnotetext{
* Corresponding author: Domenico Prisa; E-mail: beleupere@gmail.com

CREA Research Centre for Vegetable and Ornamental Crops, Council for Agricultural Research and Economics, Via dei Fiori 8, 51012 Pescia, PT, Italy.
} 
be established in utero "[2]". Within each sex, 2D:4D has been found to be associated with a variety of physical and psychological characteristics. For example, men with lower 2D:4D are more aggressive, more athletic, less feminine and more musically talented " $[3,4,5,6]$ ". Women with lower 2D:4D have higher waist-to-hip ratio, are more masculine and are more athletic " [7 \& 8]". Among men and women, 2D:4D is correlated positively with verbal intelligence and agreeableness, and negatively correlates with numerical intelligence and physical fitness "[9 \&10]". Autistic individuals have also been found to be gifted in identifying recurrent patterns, processing perceptual information, and often have exceptional memories and are less likely to misremember data "[11]". Recent study showed that 2D:4D ratio is a good measure of hand grip strength in men, but is not a robust measure of hand grip strength in women " [12]". Moreover birth weight can also be predicted using 2D:4D ratio "[13]". It was implicated that high prenatal testosterone levels in the etiology of left-handedness, autism, dyslexia, migraine, stammering and in disorders of the immune system resulting from effects on the thymus "[14]". Furtherly, first trimester exposure to oestrogen and progesterone may lead to cardiovascular anomalies such as ventricular septal defect, pulmonary stenosis, patent ductus arteriosus or transposition of the great vessels "[15]". Research has shown that male survivors of myocardial infarction have lower testosterone and higher estradiol levels than age-matched controls "[16]". In fact, incipient coronary heart disease may be traced from prenatal life. First-trimester exposure to excess levels of estrogens and progesterone may lead to cardiovascular anomalies "[15]". Although the effects of 2D:4D ratio on the cardiovascular system have been shown in means of myocardial infarction, the link between 2D:4D ratio and atherosclerotic formations have not been shown in the literature yet. Birth weight is closely associated with the health and survival of the newborn. The relationship between maternal malnutrition and consequent low birth weight babies and the perinatal morbidity and mortality is now an accepted fact. Low birth weight has been defined as weight at birth of less than 2,500 grams (5.5 pounds) "[17]". 2D:4D ratio is associated with body size and proportion at birth in men, and that men who had higher 2D:4D were shorter at birth "[18]". This is because men with higher 2D:2D ratios were exposed to little testosterone prenatally. Low 2D:4D is positively correlated with birth weight and head circumference but in males only "[18]". Association between 2D:4D and birth weight, and birth weight could be predicted most especially form the left hands "[13]". Based on that, 2D:4D ratio could serve as a means to obtain an estimate of birth weight for individuals who do not know their birth weight "[13]". Being a successful athletes, someone has to possess some unique qualities which include visual spatial awareness, speed, endurance, and strength. For example, elite footballers require spatial judgment, cardiovascular efficiency, speed, and occasionally strength. All of these qualities would be beneficial in direct male-male competition. The behavioural limits as dictated by the rules of sporting events are constantly tested by competitors, to the point where an official with total control is almost always required to police the contest "[4]". To date, athletic ability has been linked to digit ratios in a variety of sports; it is evident that female elite athletes in a range of sports had significantly lower 2D:4D digit ratios when compared to a control group of females not involved in sporting activities" [8]". Similarly, an extensive study into English professional football showed that first team players had lower mean 2D:4D ratios than reserve players and that that the tested international players had lower mean 2D:4D ratios than players yet to play internationally" [4]". 2D:4D is significantly correlated with sperm counts, estrogen, and testosterone levels "[19]". These relationships are thought to arise from the influence of prenatal androgens on 2D:4D, since adult phalangeal ratios are obtained by the 13th-14th week of gestation "[20]". More generally, a number of findings from 2D:4D research is suggestive for the hypothesis that 2D:4D may be a correlate of display traits that signal mate quality and reproductive fitness. This includes evidence for associations of 2D:4D with men's hand-grip strength "[21]", with men"s courtship behaviour "[22]".

\section{Material and methods}

\subsection{Study location}

The study was conducted in one selected areas in Ekowe community, namely Federal Polytechnic, Ekowe campus. Anthropometric measurements of the required parameters of these students were taken.

\subsection{Research Participants}

The subjects that participated in this study were undergraduates of Federal Polytechnic, Ekowe, Bayelsa State, Nigeria. $(n=299$, between the age of 18-45yrs).

\subsection{Data collection technique}

Samples for the present cross-sectional study were randomly collected from undergraduates in Federal Polytechnic, Ekowe. 


\subsection{Method}

An informed verbal consent was taken from the students who are willing to participate in the survey. In order to reduce errors, Digit length was measured on the ventral surface of the hand from the basal crease of the digit to the tip using a sliding venier caliper (MicroMak, USA) measuring to $0.05 \mathrm{~mm}$, according to Manning et al., 1998 "[23]". Anthropometric measurements were done twice independently and the mean of the two measurements was taken as the actual value.

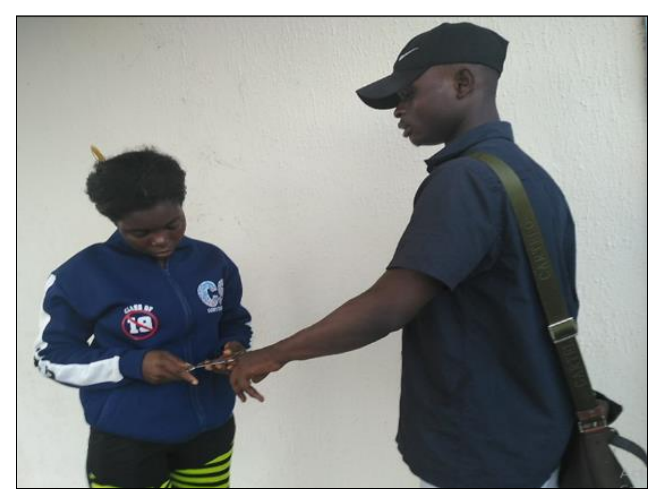

Figure 1 Measurement of Digits of student

\subsection{Instruments of data collection}

All the measurements were recorded in the nearest centimetre $(\mathrm{cm})$ using standardized anthropometric measuring instruments; Sliding vernier calliper, measuring tape.

\subsection{Inclusion and exclusion criteria}

\subsubsection{Inclusion Criteria}

- $\quad$ All subjects were students of Federal Polytechnic, Ekowe.

- All subjects were mentally and physically fit.

- All subjects were free from hand deformity

\subsubsection{Exclusion Criteria}

- Any subject that does not meet the above set inclusion criteria.

- Also any subject that has some form of deformity in the body areas targeted for anthropological assessment that could hinder accurate measurement.

\subsection{Statistical Analysis}

The data obtained was computed and analysed using Microsoft excel 2007 computer software. Descriptive statistics were generated using the software. The significance difference was tested by Z-test, p-value less than 0.05 is considered as significant difference. The statistical methods like mean, standard deviation (SD), standard error (SE), and Z-test were used for the statistical analysis.

\section{Results}

Table 1 mean values of 2D:4D

\begin{tabular}{|c|c|l|l|l|l|}
\hline S/N & SEX & \multicolumn{2}{|c|}{ 2D RATIO } & \multicolumn{2}{c|}{ 4D RATIO } \\
\hline \multirow{2}{*}{1} & \multirow{2}{*}{ MALE } & RT HAND & LT HAND & RT HAND & LT HAND \\
\cline { 3 - 6 } & & $7.56 \pm 0.04$ & $7.56 \pm 0.04$ & $7.74 \pm 0.04$ & $7.74 \pm 0.04$ \\
\hline \multirow{2}{*}{2} & FEMALE & RT HAND & LT HAND & RT HAND & LT HAND \\
\cline { 3 - 6 } & & $7.43 \pm 0.05$ & $7.43 \pm 0.05$ & $7.76 \pm 0.05$ & $7.76 \pm 0.05$ \\
\hline
\end{tabular}


Table 2 Z- test for same sex

\begin{tabular}{|c|c|c|c|}
\hline S/N & SEX & 2DR \& 2DL & 4DR \&4DL \\
\hline 1 & Male & No sig. Difference & No sig. Difference \\
\hline 2 & Female & No sig.difference & No sig. Difference \\
\hline
\end{tabular}

Table 3 Z- test for different sex

\begin{tabular}{|c|c|c|c|c|}
\hline SEX & 2DR \& 2DR & 2DL \& 2DL & 4DR \& 4DR & 4DL\&4DL \\
\hline $\begin{array}{l}\text { Male \& } \\
\text { Female }\end{array}$ & $\begin{array}{c}\text { Sig. Difference } \\
(\mathrm{p}<0.05)\end{array}$ & $\begin{array}{c}\text { Sig. Difference } \\
(\mathrm{p}<0.05)\end{array}$ & $\begin{array}{c}\text { No sig. Difference } \\
(\mathrm{p}>0.05)\end{array}$ & $\begin{array}{c}\text { No sig. Difference } \\
(\mathrm{p}>0.05)\end{array}$ \\
\hline
\end{tabular}

Table 4 male and female 2D: 4D ratios

\begin{tabular}{|c|c|c|}
\hline Trait & $\begin{array}{c}\text { MALE } \\
\text { 2D:4D RATIO }\end{array}$ & $\begin{array}{c}\text { FEMALE } \\
\text { 2D:4D RATIO }\end{array}$ \\
\hline Rt hand & $0.98 \pm 0.04$ & $0.96 \pm 0.05$ \\
\hline Lt hand & $0.98 \pm 0.04$ & $0.96 \pm 0.05$ \\
\hline \multicolumn{2}{|c|}{ Mean \pm S.E; All values are in centimeters $(\mathrm{cm})$}
\end{tabular}

\section{Discussion}

The results of this present study showed that, the mean 2D length of right and left hands of male individuals have shown to be higher than the 2D length of the female individuals with values $7.56 . \mathrm{cm}$ for male $2 \mathrm{D}$ right and $7.56 \mathrm{~cm}$ for $2 \mathrm{D}$ left, then $7.43 \mathrm{~cm}$ for $2 \mathrm{D}$ right and $7.43 \mathrm{~cm} 2 \mathrm{D}$ left for the females.

The mean values of the male 4D length tend to be smaller than the females 4D with values for both right and left hands as $7.74 \mathrm{~cm}$ for $4 \mathrm{D}$ right and $7.74 \mathrm{~cm}$ for $4 \mathrm{D}$ left for males and $7.76 \mathrm{~cm}$ for $4 \mathrm{D}$ right and $7.76 \mathrm{~cm}$ for left $4 \mathrm{D}$ for the female students ( table 1 ).

But the mean values of 2D:4D ratio of male right and left hand are $0.98 \pm 0.04$ and $0.98 \pm 0.04$. Also the mean values of 2D:4D ratio of the female right and left hands are $0.96 \pm 0.05$ and $0.96 \pm 0.05$ respectively ( table 4 ) which finding contradict the results of Manning et al., 1998 '[23]" were the females have a higher mean values than the males.

Findings from these results using Z-test showed that there no statistical significant difference between male 2D right and left, 4D right and left ( $P>0.05$ ) as shown in (table 2). Also, no significant difference in the female 2D right and left; $4 \mathrm{D}$ right and $4 \mathrm{D}$ left as shown in (table 2 ) respectively.

The present results showed 2D right of male and female to be significantly different. In addition, the male 2D left and female 2D left has also shown significant difference $(\mathrm{P}<0.05)$ which was earlier published by Oladipo et al.,2009 "[24]".

\section{Conclusion}

This study provides numerical evidence that, the males have a significantly longer 2D ratio for both right and left hands than the females, while the females have longer right and left 4D length than the males.

This is suggestive of the fact, that prenatal hormones have played fundamental roles and have strong influence on humans, during developmental stages.

We recommend 2D: 4D as a pointed for specific health analysis for early treatment of disease conditions. 


\section{Compliance with ethical standards}

\section{Acknowledgments}

We sincerely appreciate the Management, Staff Members and the Students of Federal Polytechnic Ekowe, for their moral support and allowing the research team to carry out the research without molestation thus, making it itch free for the research period.

\section{Disclosure of conflict of interest}

The authors declare no competing interests.

\section{Statement of informed consent}

Verbal informed consent was sought from each of the volunteered participants (students) before commencement of measurements. Participants were properly enlightened on the purpose and procedure of the study.

\section{References}

[1] Baker F. Anthropological notes on the human hand. American Anthropologist. 1888; 1: 51- 76.

[2] Csatho A, Osvath A, Bicsack E, Karadi K, Manning J, Kallai J. Sex role identity related to the ratio of second to fourth digit length in women. Biological Psychology. 2003; 62: 147-156.

[3] Bailey AA, Hurd PL. Finger length ratio correlates with Physical aggression in men but not in women. Biological Psychology. 2005; 68; 215- 222.

[4] Manning JT, Taylor RP. Second to fourth digit ratio and male ability in sport: implications for sexual selection in humans. Evolution and Human Behavior. 2001; 22: 61-69.

[5] Rammsayer TH, Troche SJ. Sexual dimorphism in second-to-fourth digit ratio and its relation to gender-role orientation in males and females. Personality and Individual Differences. 2007; 42: 911-920.

[6] Sluming VA, Manning JT. Second to fourth digit ratio in elite musicians: evidence for musical ability as an honest signal of male fitness. Evolution and Human Behavior. 2000; 21 : 1-9.

[7] Csatho A, Osvath A, Karadi K, Bisak E, Manning JT, and Kallai J. Spatial navigation related to the second to fourth digit length in women. Learning and. Individual Difference. 2003; 13: 239-249.

[8] Pokrywka L, Rachon D, Suchecka-Rachon K, Bitel L. The second to fourth digit ratio in elite and non-elite female athletes. American Journal of Human Biology. 2005; 17: 796-800.

[9] Hönekopp J, Voracek M, Manning JT. 2nd to 4th digit ratio (2D:4D) and number of sex partners: Evidence for effects of prenatal testosterone in men. Psychoneuroendocrinology. 2006; 3: 30-37.

[10] Luxen MF, Buunk BP. Second-to-fourth digit ratio related to Verbal and Numerical Intelligence and the Big Five. Personality and Individual Differences. 2005; 39: 959966.

[11] Mottron L. Changing perceptions: The power of autism. Nature. 2011; 479: 33-35.

[12] Lu H, Shen D, Wang L, Niu S, Bai C, Ma Z. Digit ratio (2D:4D) and handgrip strength are correlated in women (but not in men) in Hui ethnicity. Early Human Development. 2017; 109: 21-5.

[13] Danborno B, Adebisi SS, Adelaiye AB, Ojo SA. Relationship between digit ratio (2D:4D) and birth weight in Nigerians. Anthropologist. 2010; 12(2): 127-130.

[14] Geschwind,N and Galaburda. A.M. Cerebral lateralization. Biological mechanisms, associations and pathology: I. A hypothesis and a program for research. Archives of Neurology. 1985; 42: 428-459.

[15] Heinonen, OP. Slone, D., Monson, RR. Hook,EB. and Shapiro S. Cardiovascular birth defects and antenatal exposure to female hormones. England Journal of Medicine. 1977; 296: 67-70.

[16] Aksüt, SV., Aksüt, G., Karamehmetoglu, A. and Oram. E. The determination of serum estradiol, testosterone and progesterone in acute myocardial infarction. Japan Heart Journal. 1986; 27: 825-837.

[17] WHO. Guidelines on optimal feeding of low birth-weight infants in low- and middle-income countries. Geneva, World Health Organization. 2011. 
[18] Ronalds, G., Phillips, DI., Godfrey, KM., Manning JT. The ratio of second to fourth digit lengths: a marker of impaired fetal growth?. Early Human Development. 2002; 68(1): 21-26.

[19] Manning, JT and Diane S. The Ratio of 2nd to 4th Digit Length: A Predictor of Sperm Numbers and Concentrations of Testosterone, Luteinizing Hormone and Oestrogen. 1998; 16: 145-152.

[20] Garn, SM., Burdi, AR., Babler, WJ. and Stinson S. Early prenatal attainment of adult meta-carpal- phalangeal rankings and proportions. American Journal of Physical Anthropology. 1975; 43: 327-332.

[21] Fink, B., Thanzami, V., Seydel, H., Manning JT. Digit ratio and hand grip strength in German and Mizos men: crosscultural evidence for an organising effect of prenatal testosterone on strength. Am J Hum Biol. 2006; 18: 776782.

[22] Roney, JR. and Maestripieri D. Relative digit lengths predict men's behavior and attractiveness during social interactions with women. Human Nature. 2004; 15(3): 271-282.

[23] Manning JT, Scutt, D., Wilson, J. and Lewis-Jones DI. The ratio of 2nd to 4th digit length: a predictor of sperm numbers and concentrations of testosterone, luteinizing hormone and oestrogen. Hum Reprod. 1998 Nov;13 (11):3000-4.

[24] Oladipo, GS., Fawehinmi, HB., Edi-bamode, E, Osunwoke, EA. and Kenneth O. Second to Fourth Digit Ratio in Nigerian Igbos and Yorubas. Scientific Research and Essay. 2009; 4(10): 11461148. 